\title{
Real-time precise point positioning augmented with high-resolution numerical weather prediction model
}

\author{
Karina Wilgan $^{1} \cdot$ Tomasz Hadas $^{1} \cdot$ Pawel Hordyniec $^{1} \cdot$ Jaroslaw Bosy $^{1}$
}

Received: 28 August 2016/Accepted: 17 March 2017/Published online: 23 March 2017

(c) The Author(s) 2017. This article is an open access publication

\begin{abstract}
The tropospheric delay is one of the major error sources in precise point positioning (PPP), affecting the accuracy and precision of estimated coordinates and convergence time, which raises demand for a reliable tropospheric model, suitable to support PPP. In this study, we investigate the impact of three tropospheric models and mapping functions regarding position accuracy and convergence time. We propose a routine to constrain the tropospheric estimates, which we implemented in the in-house developed real-time PPP software. We take advantage of the high spatial resolution $\left(4 \times 4 \mathrm{~km}^{2}\right)$ numerical weather prediction Weather Research and Forecasting (WRF) model and near real-time GNSS data combined by the least-squares collocation estimation to reconstruct the tropospheric delays. We also present mapping functions calculated from the WRF model using the ray-tracing technique. The performance tests are conducted on 14 Polish EUREF Permanent Network (EPN) stations during 3 weeks of different tropospheric conditions: calm, standard and severe. We consider six GNSS data processing variants, including two commonly used variants using a priori ZTD and mapping functions from UNB3m and VMF1-FC models, one with a priori ZTD and mapping functions calculated directly from WRF model and three variants using the aforementioned mapping functions but with ZTD model based on GNSS and WRF data used as a priori troposphere and to constrain tropospheric estimates. The application of a high-resolution GNSS/WRF-based
\end{abstract}

Karina Wilgan

karina.wilgan@igig.up.wroc.pl

1 Institute of Geodesy and Geoinformatics,

Wroclaw University of Environmental and Life Sciences,

Grunwaldzka 53, 50-357 Wrocław, Poland
ZTD model and mapping functions results in the best agreement with the official EPN coordinates. In both static and kinematic modes, this approach results in an average reduction of 3D bias by 20 and $10 \mathrm{~mm}$, respectively, but an increase of 3D SDs by 1.5 and $4 \mathrm{~mm}$, respectively. The application of high-resolution tropospheric model also shortens the convergence time, for example, for a $10 \mathrm{~cm}$ convergence level, from 67 to $58 \mathrm{~min}$ for the horizontal components and from 79 to $63 \mathrm{~min}$ for the vertical component.

Keywords GNSS · Precise point positioning (PPP) . Tropospheric model · Mapping functions - Real-time . Numerical weather prediction (NWP) · Least-squares collocation

\section{Introduction}

Precise point positioning (PPP) is now a well-established and commonly used strategy by the Global Navigation Satellite System (GNSS) community, although the realtime PPP is still under development. Among the many advantages of real-time PPP such as robust processing, single-receiver only solution, worldwide coverage, straightforward error mitigation or a direct support of additional parameters, this approach still requires a rather long initialization time. The consequence of using the ionospheric-free linear combination is that the ambiguities are no longer integer values. To accelerate the convergence time, many authors focused on fixing carrier phase ambiguities to integers ( $\mathrm{Li}$ et al. 2014; Ge et al. 2008; Mervart et al. 2008). Another factor is that a change in constellation geometry is required to efficiently de-correlate the tropospheric delay, receiver clock error and receiver height. An 
alternative solution is to provide tropospheric corrections interpolated from nearby reference stations ( $\mathrm{Li}$ et al. 2011) or in the form of optimal fitting coefficients for the regional zenith total delay (ZTD) model (Shi et al. 2014). With highly accurate tropospheric corrections, it is possible to fix the tropospheric delay in PPP processing, hence reducing the number of unknown parameters. However, there is a risk of poor accuracy of the vertical component determination in case the provided model is shifted with respect to the real tropospheric conditions. It was shown by Hadas et al. (2013) that near real-time ZTD estimates from GNSS processing may improve GNSS PPP results and that using the model based on in situ meteorological parameters may significantly bias the receiver height.

In this study, we propose an alternative approach to introducing the external high-quality regional tropospheric delay model to constrain tropospheric estimates. A similar approach has already been investigated by Yao et al. (2014), using a GNSS-based global ZTD model and introducing a virtual observation into the system of equations, which allows isolating and fixing the tropospheric delay. de Oliveira et al. (2017) investigated constraining tropospheric delay with regional GNSS-based ZTD model in real-time kinematic PPP. Although both solutions have a positive impact on PPP convergence time of about $15 \%$, they have one major disadvantage-receiver must be located inside the coverage of a reference network.

For the aforementioned reasons, the GNSS community has started utilizing global numerical weather prediction (NWP) models to reduce the tropospheric impact on the signal propagation, by providing a priori ZTDs and mapping functions (MF) (Kouba 2008; Boehm et al. 2009; Urquhart et al. 2014). There are many scientific initiatives focused on combining the GNSS products with NWP models such as the EIG EUMETNET GPS Water Vapour Programme (E-GVAP, egvap.dmi.dk) or COST Action ES1206 GNSS4SWEC (Guerova et al. 2016, gnss4swec.knmi.nl).

The advantage of using NWP models in PPP is their availability in real time and an agreement with current meteorological data. The limitation is the quality since they are based on global NWP of relatively low spatial resolution of a grid spacing of several degrees and low temporal resolution of usually $6 \mathrm{~h}$. The reported accuracy of NWPbased ZTD models is several centimeters (Snajdrova et al. 2006; Douša et al. 2016), which may not be enough to fix ZTD in precise applications, although Ibrahim and ElRabbany (2011) used the NOAATrop model to support PPP and noticed that the convergence time was accelerated by $15 \%$ for vertical component compared to the standard PPP.

To overcome limitations of global NWP models, we propose to use a regional NWP model of high spatial resolution of $4 \mathrm{~km}$ and a temporal resolution of $1 \mathrm{~h}$. Such NWP model may be used to derive MF coefficients with ray-tracing technique, as well as to provide external a priori information on ZTD at any location inside the NWP coverage. Zus et al. (2014) already showed that the real-time delivery of NWP-based tropospheric products such as slant delays, horizontal gradients of first order and mapping functions is possible with high precision.

In the next section, we present the high-resolution a priori model and mapping functions based on the NWP Weather Research and Forecasting (WRF) model (Skamarock et al. 2008). In the subsequent section, we describe the PPP strategy in more detail and present the processing variants. In the following section, we study the impact of the processing variants on coordinates precision, accuracy and solution convergence time. The last section summarizes the study.

\section{Tropospheric model}

We compare the impact of using different tropospheric models and MFs in real-time PPP. We use two standard tropospheric models available in real time, namely UNB3m (Leandro et al. 2006) and Forecast Gridded Vienna Mapping Function 1-VMF1-FC (Boehm et al. 2009), considered as the state-of-art models. In UNB3m model, a lookup table of surface meteorological parameter values is combined with the Saastamoinen vertical propagation delay model (Saastamoinen 1973) and Niell Mapping Functions (NMF, Niell 1996) to provide a priori zenith hydrostatic delay (ZHD) and zenith wet delay (ZWD) as well as hydrostatic and wet MFs. In the VMF1-FC model, the product from Vienna University of Technology is used (http://ggosatm.hg.tuwien.ac.at/ DELAY/GRID/), which is based on the European Centre for Medium-Range Weather Forecasts (ECMWF) model to provide the same set of parameters.

In this study, we present a high-resolution tropospheric model based on WRF predictions. This section describes the data and methodology used to calculate the tropospheric model, which is divided into two parts: (1) ZTD used as an a priori troposphere to constrain tropospheric estimates and (2) MFs used to reduce the zenith delay to the slant delay. We obtain the high-resolution ZTD model from two sources, the regional GNSS data and NWP model WRF, integrated into the least-squares collocation procedure using software COMEDIE (Collocation of Meteorological Data for Interpretation and Estimation of Tropospheric Path delays) developed at ETH Zürich (Eckert et al. 1992a, b; Troller et al. 2003; Hurter and Maier 2013). The high-resolution MFs are calculated using the ray-tracing technique (Hobiger et al. 2008) through the WRF model (Kryza et al. 2013). 


\section{Data}

The high-resolution a priori ZTD is based on meteorological parameters from WRF model integrated with near realtime GNSS data. The data period consists of 3 weeks, which represent three different seasons and three different tropospheric conditions: (1) standard troposphere, December 2-8, 2015; (2) calm troposphere, May 2-8, 2016; and (3) severe troposphere, August 28-September 3, 2016, when a heavy precipitation across Poland occurred.

The first data source for the a priori model is near realtime ZTD, computed using the Bernese GNSS Software version 5.2 (Dach et al. 2015) with the processing routines described in Bosy et al. (2012). Figure 1 shows the location of 272 GNSS stations in Poland and adjacent area used to build the collocation model. The model is tested for 14 Polish GNSS stations, which are a part of the EUREF Permanent Network (EPN, www.epncb.oma.be) (Fig. 1, red dots).

The second data source for the a priori model is the NWP WRF model, computed and provided by the University of Wroclaw (www.meteo.uni.wroc.pl, Kryza et al. 2013). The current configuration provides meteorological parameters on $4 \times 4 \mathrm{~km}^{2}$ horizontal grid with 47 vertical levels covering the whole area of Poland. The forecasts of meteorological parameters air pressure $p$, temperature $T$ and water vapor partial pressure $e$ with $1 \mathrm{~h}$ resolution are given 4 times a day. We use the analysis at $0: 00,6: 00,12: 00,18: 00$ UTC and the following $5 \mathrm{~h}$ of predictions until the next analysis. The total refractivity $N_{\text {tot }}$ is calculated from the WRF meteorological parameters (Essen and Froome 1951):

$N_{\mathrm{tot}}=k_{1} \frac{p-e}{T}+k_{2} \frac{e}{T}+k_{3} \frac{e}{T^{2}}$

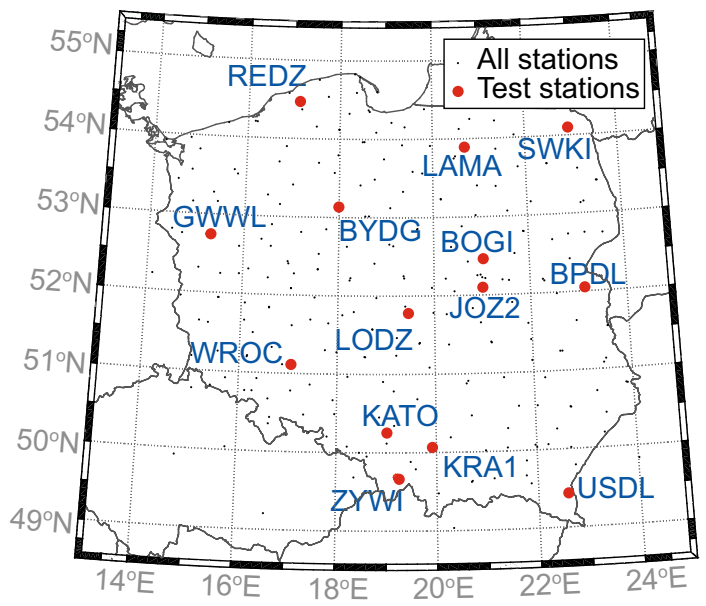

Fig. 1 Location of GNSS stations used in this study; red circles denote the EPN stations for which the model is tested where $\quad k_{1}=77.689 \mathrm{~K} / \mathrm{hPa}, \quad k_{2}=71.2952 \mathrm{~K} / \mathrm{hPa}$ and $k_{3}=375,463 \mathrm{~K}^{2} / \mathrm{hPa}$ are empirically determined coefficients given by Rüeger (2002) as 'best average.' These coefficients provide an optimally weighted approach among currently available solutions, which should improve robustness and reliability of calculated refractivity.

\section{High-resolution a priori ZTD}

The high-resolution a priori $\mathrm{ZTD}_{\text {COMEDIE }}$ is calculated from WRF and GNSS data using the collocation software COMEDIE. The thorough description of the least-squares collocation technique and the $\mathrm{ZTD}_{\text {COMEDIE from Polish }}$ data can be found in Wilgan et al. (2017). Basically, the collocation estimates the deterministic part, the signal and the noise of each measurement. Using the estimated coefficients of the deterministic part and the signal, one can obtain the considered parameter at any point and any time. These coefficients are calculated from WRF and GNSS data simultaneously. In this study, we interpolate the ZTD $_{\text {COMEDIE }}$ every $5 \mathrm{~min}$ at the locations of 14 test EPN stations. The test station is always locally excluded from the collocation procedure, so the interpolation method can also be verified. We compare the outputs from COMEDIE with the EPN combined weekly solution tropospheric products (www.epncb.oma.be). The biases and SDs between $\mathrm{ZTD}_{\mathrm{EPN}}$ and $\mathrm{ZTD}_{\mathrm{COMEDIE}}$ for all 14 stations are presented in Fig. 2.

As seen from Fig. 2, the SDs of residuals are at an average level of $10 \mathrm{~mm}$. The biases are strongly dependent on the tropospheric conditions. For the calm period, the biases are usually the smallest and increase with the variations of the troposphere; thus, for the severe period, the

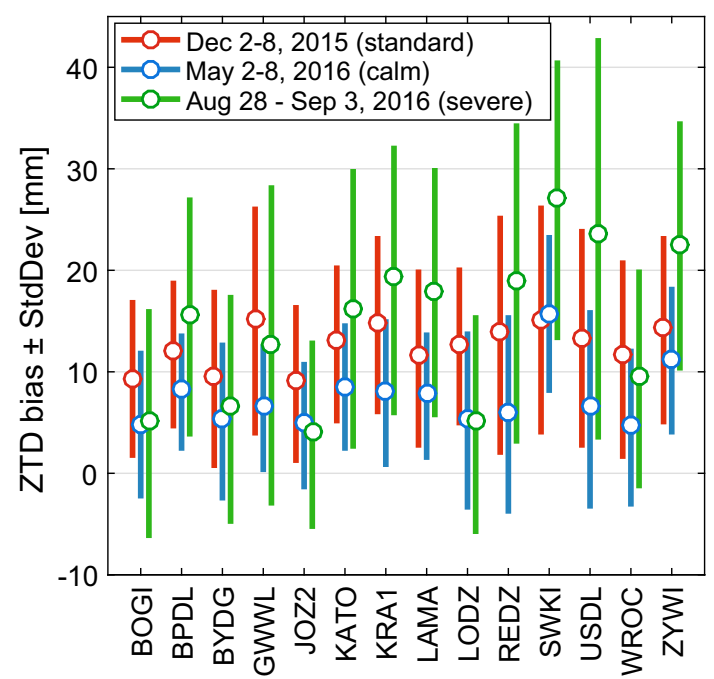

Fig. 2 Mean biases and SDs of residuals $Z_{T D} D_{\text {EPN }}-Z_{\text {TDD }}$ COMEDIE $(\mathrm{mm})$ 
biases are generally the largest. Moreover, for stations that are not surrounded by many other GNSS stations, such as SWKI or ZYWI, the collocation model depends mainly on WRF, which is biased with respect to the GNSS data (Wilgan et al. 2017). Thus, those stations exhibit larger biases than stations that are surrounded by many other GNSS stations, such as BYDG or LODZ. For the application into the PPP software, the mean biases for each station and each period are removed from the ZTD time series. This procedure is also feasible in real-time mode, for example, using the mean biases from the time series of the previous week.

We compare the ZTDs obtained from three models: COMEDIE, VMF1-FC and UNB3m with the $\mathrm{ZTD}_{\mathrm{EPN}}$ for two representative stations, BPDL, located in the lowlands and ZYWI, located in the mountains (Fig. 3). The mean biases for the $\mathrm{ZTD}_{\mathrm{COMEDIE}}$ have already been removed according to the values shown in Fig. 2 .

Figure 3 shows the ZTDs from UNB3m and VMF1-FC models calculated with $6 \mathrm{~h}$ resolution. The $\mathrm{ZTD}_{\mathrm{UNB} 3 \mathrm{~m}}$ values change only every GPS week. Thus, they do not represent the tropospheric time variability. For stations located in the lowlands, such as BPDL, the $\mathrm{ZTD}_{\mathrm{VMF} 1-\mathrm{FC}}$ follows the general trend, but it cannot reflect any sudden changes in ZTD behavior, because of the $6 \mathrm{~h}$ resolution. Moreover, in a mountainous area, as for station ZYWI, the VMF1-FC model underestimates the ZTD values. The $\mathrm{ZTD}_{\mathrm{COMEDIE}}$ follows the general trend of $\mathrm{ZTD}_{\mathrm{EPN}}$ and detects better the rapid changes, although sometimes the magnitude of the variation is smaller.

\section{Mapping functions}

The methodology to calculate MFs from the WRF outputs (WRFMF) is adopted from Boehm and Schuh (2004), where the authors explain how to calculate Vienna Mapping Function (VMF) and associated ray-traced tropospheric delays.

The VMF and WRFMF are in the form of a continued fraction (Herring 1992) depending on an elevation angle el:

$\mathrm{MF}(\mathrm{el})=\frac{1+\frac{a}{1+\frac{b}{1+c}}}{\sin (\mathrm{el})+\frac{a}{\sin (\mathrm{el})+\frac{b}{\sin (\mathrm{el})+c}}}$

The wet and hydrostatic MFs are derived separately. Thus, two sets of coefficients $a, b, c$ are required: $a_{\mathrm{h}}, b_{\mathrm{h}}, c_{\mathrm{h}}$ for the hydrostatic MF and $a_{\mathrm{w}}, b_{\mathrm{w}}, c_{\mathrm{w}}$ for wet MF. Boehm and Schuh (2004) present two approaches to calculating MF coefficients, i.e., 'fast' and 'rigorous.' In mid-latitudes, as is the case for Poland, these two methods differ only by $3 \mathrm{~mm}$ of station height for $5^{\circ}$ elevation angle and the 'fast' approach is about 10 times faster than 'rigorous.'

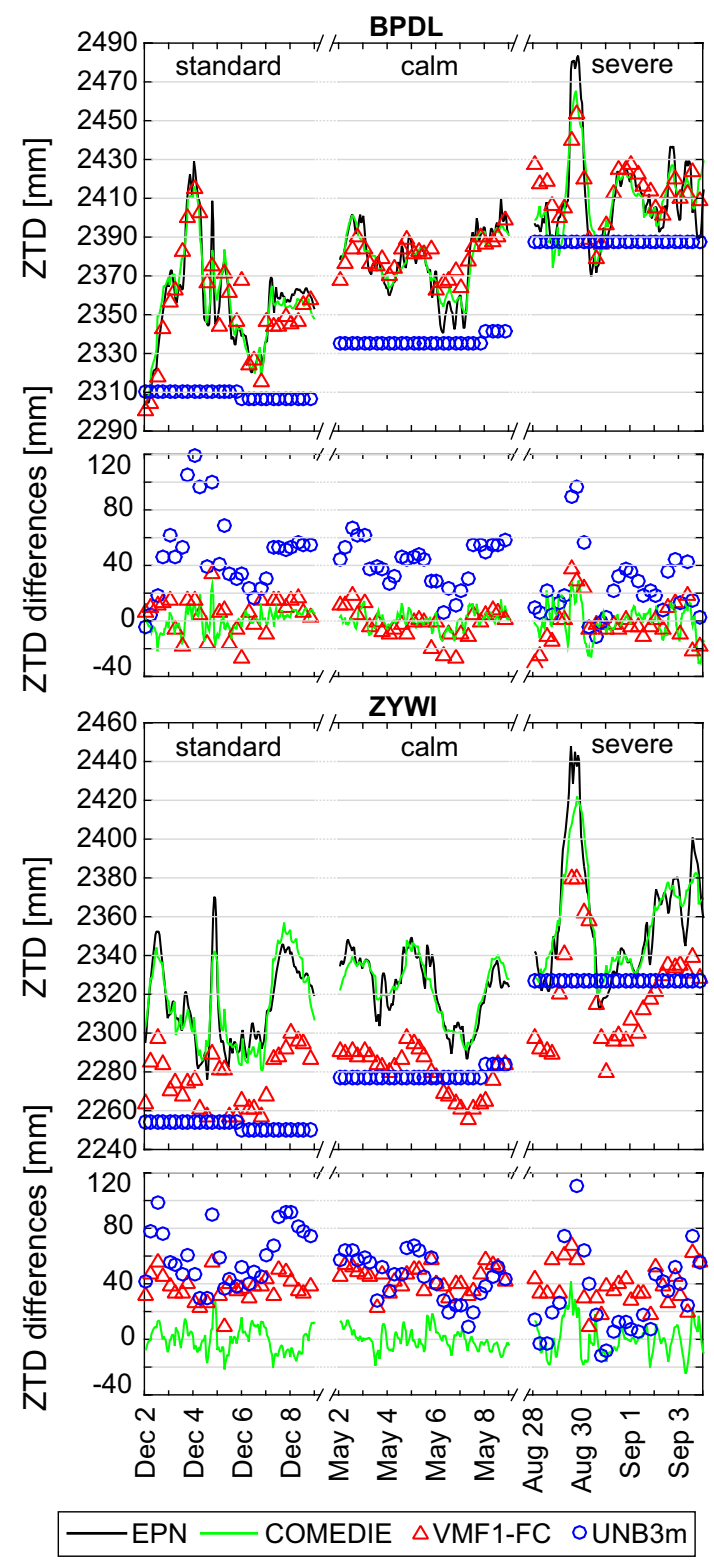

Fig. 3 ZTDs obtained from four models and ZTD differences between EPN and models for two representative stations BYDG (top) and ZYWI (bottom)

Considering the feasibility for the real-time applications, the 'fast' approach is adopted in this study. In this approach, only $a$-coefficients are calculated based on zenith and slant delays for an elevation angle of $3.3^{\circ}$ using raytracing technique through WRF model according to the assumptions in Table 1. We applied the method of linear propagation in geometry optics approximation following the Snell's law as described by Hobiger et al. (2008).

The hydrostatic $\mathrm{MF}_{\mathrm{h}}$ and wet $\mathrm{MF}_{\mathrm{w}}$ mapping functions are calculated for each station applying $1 \mathrm{~h}$ temporal resolution of the WRF model: 
Table 1 Summary of the ray-tracing configurations

Ray-path model

Bent-2D model with straight-line ray pieces and no out-of-plane components

The contribution of water droplets and ice crystals in the atmosphere is neglected

Refractivity coefficients $k_{1}, k_{2}$ and $k_{3}$ as proposed by Rüeger (2002) as 'best average'

Reference system

NWP geocentric latitudes assumed to be geodetic latitudes

Formula for earth radius

Azimuth-dependent Euler radius

Geoid undulation

Earth Gravitational Model (EGM96)

Meteorological field

WRF model with staggered geopotential layers as standard vertical coordinate

Horizontal interpolation

Vertical interpolation

Supplementary atmosphere

Vertical resampling according to Rocken et al. (2001)
2-D Shepard (1968) weighted mean method

Exponential: air pressure, water vapor pressure

Linear: air temperature

U. S. Atmosphere (1976) up to $86 \mathrm{~km}$

$10 \mathrm{~m}(0-2 \mathrm{~km}), 20 \mathrm{~m}(2-6 \mathrm{~km}), 50 \mathrm{~m}(6-16 \mathrm{~km}), 100 \mathrm{~m}(16-36 \mathrm{~km})$, $500 \mathrm{~m}$ (above $36 \mathrm{~km}$ )

$$
\begin{aligned}
& \mathrm{MF}_{\mathrm{h}}=\frac{\mathrm{SHD}+d_{\text {geo }}}{\mathrm{ZHD}} \\
& \mathrm{MF}_{\mathrm{w}}=\mathrm{SWD} / \mathrm{ZWD}
\end{aligned}
$$

where $d_{\text {geo }}$ denotes the geometric bending effect, SHD and SWD are the slant hydrostatic and wet delays calculated from ray-tracing for $\mathrm{el}=3.3^{\circ}$. The coefficients $b_{\mathrm{h}}=0.002906$ and $c_{\mathrm{h}}=0.0634+0.0014 \cos (2 \varphi)$, where $\varphi$ is the geodetic latitude, are taken from the hydrostatic part of the isobaric mapping function (IMF). Wet coefficients $b_{\mathrm{w}}=0.00146$ and $c_{\mathrm{w}}=0.04391$ are taken from NMF. The coefficients $a_{\mathrm{h}}$ and $a_{\mathrm{w}}$ are calculated by inverting the continued fraction (2) for the $\mathrm{MF}_{\mathrm{h}}$ and $\mathrm{MF}_{\mathrm{w}}$, respectively.

We compare the values of WRFMF with MFs from UNB3m and VMF1-FC. The time resolution of MFs from UNB3m and VMF1-FC models is $6 \mathrm{~h}$, while the resolution of WRFMF is $1 \mathrm{~h}$ due to the resolution of the WRF model. For GNSS processing, the linear interpolation between two successive MF values is applied. Figure 4 presents the hydrostatic and wet MFs from all models for different elevation angles, ranging from $3^{\circ}$ to $11^{\circ}$. For larger elevation angles, the differences between MFs are negligible. The first presented elevation angle is el $=3^{\circ}$, because in the 'fast' approach, the $a$-coefficients are determined for $\mathrm{el}=3.3^{\circ}$. In our processing, the cutoff angle is set to $5^{\circ}$, which is a most commonly used cutoff angle (Boehm and Schuh 2004; Zus et al. 2014). Table 2 presents the mean biases and SDs between standard MFs and WRFMF for $\mathrm{el}=5^{\circ}$.

As Table 2 shows, the hydrostatic MFs are very stable in time. For $5^{\circ}$ elevation angle, the biases between VMF1-FC/ UNB3m and WRFMF are close to zero with SDs of 0.0037

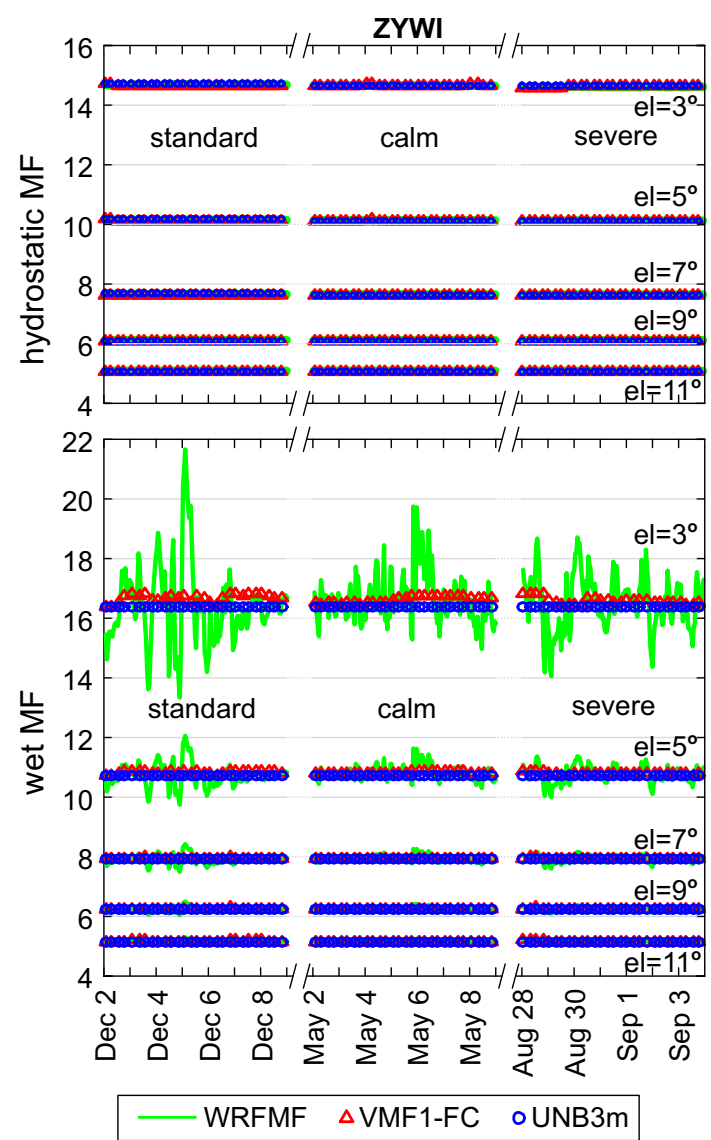

Fig. 4 Comparison of the hydrostatic MFs (top) and wet MFs (bottom) from three models: WRFMF, VMF1-FC and UNB3m, for representative station ZYWI

and 0.0046 units, respectively. Thus, there is almost no difference between the models. Figure 4 shows that for all elevation angles, the hydrostatic MFs for all models are 
Table 2 Mean biases and SDs of MF differences of VMF1-FC/ $\mathrm{UNB} 3 \mathrm{~m}$ and WRFMF averaged over 14 stations for three periods

\begin{tabular}{|c|c|c|c|c|c|}
\hline \multirow[t]{2}{*}{ Period } & & \multicolumn{2}{|c|}{ VMF1-FC-WRFMF } & \multicolumn{2}{|c|}{ UNB3m-WRFMF } \\
\hline & & Bias (unit) & SD (unit) & Bias (unit) & SD (unit) \\
\hline \multirow[t]{2}{*}{ December 2-8, 2015} & Hydrostatic & -0.0025 & 0.0050 & 0.0151 & 0.0051 \\
\hline & Wet & 0.0806 & 0.3156 & 0.0524 & 0.3256 \\
\hline \multirow[t]{2}{*}{ May 2-8, 2016} & Hydrostatic & 0.0049 & 0.0026 & 0.0071 & 0.0037 \\
\hline & Wet & -0.0388 & 0.2842 & -0.1136 & 0.2880 \\
\hline \multirow[t]{2}{*}{ August 28-September 3, 2016} & Hydrostatic & -0.0019 & 0.0034 & 0.0018 & 0.0048 \\
\hline & Wet & 0.0457 & 0.2320 & 0.0040 & 0.2409 \\
\hline
\end{tabular}

Elevation angle el $=5^{\circ}$ almost identical. The wet WRFMF exhibits more stochastic behavior. The figure also shows that for elevation angle el $=3^{\circ}$, the wet MF displays high variability, but variations show more oscillating characteristics around mean value that we attribute to WRF model feature. Moreover, the cutoff angle in the software is set up to $5^{\circ}$, so the MFs at the elevation angle of $3^{\circ}$ are not used for the positioning, but shown to present the variability of the wet WRFMF. The average SDs for el $=5^{\circ}$ between $\mathrm{VMF} 1-\mathrm{FC} / \mathrm{UNB} 3 \mathrm{~m}$ and WRFMF are at similar level of 0.28 units, which accounts for about $3 \%$ of the mapping function value. Thus, we may conclude that there are only small variations between wet MFs from standard models and WRFMF, although, due to the $1 \mathrm{~h}$ resolution of WRFMF, it may reflect the state of the troposphere more accurately.

\section{Precise point positioning}

We estimate static, continuous kinematic and reinitialized kinematic receiver coordinates using real-time PPP. Here we present the strategy and the processing variants of different combinations of a priori troposphere models and mapping functions.

\section{GNSS data processing model}

We use self-developed GNSS-WARP software (Hadas 2015) designed for real-time GNSS data processing, with a classical PPP model implemented, which utilizes an ionospheric-free combination of pseudoranges and carrier phase measurements. All IERS Convention (2010) displacement models required for PPP are included in the software to ensure the consistency between GNSS data processing and product estimation strategy, so the final coordinates are consistent with the current ITRF realization (Kouba 2015). In this study, we process data in the simulated real-time mode of the software. We use broadcast ephemeris, orbit and clock corrections from IGS Real-Time Service (RTS) streams (www.igs.org/rts/products) recorded with BKG Ntrip Client (BNC) software. It was verified by the authors that all of the parameters estimated in the simulated realtime mode are exactly the same as in the real-time mode.

\section{Processing variants}

We estimate three types of coordinates, namely static, continuous kinematic and reinitialized kinematic. Figure 5 explains the differences between these types for a sample station LODZ. In the first two types, the filter is initialized only at the beginning of the processing, while in the third solution, we reinitialize the PPP filter to perform the initialization process repeatedly every $3 \mathrm{~h}$ in order to investigate the convergence time.

We perform the processing in six variants listed in Table 3. The first two variants reflect the standard PPP solution with a priori ZHD, ZWD as well as MFs from UNB3m or VMF1-FC models. In the third variant WRFMF, the a priori ZTD is represented as an integral of total refractivity calculated from WRF outputs using (1), with the WRFMFs also calculated from WRF model. The next three variants use the same round of mapping functions, but with $\mathrm{ZTD}_{\mathrm{COMEDIE}}$ as the a priori ZTD and to constrain the ZTD estimates. Due to the $5 \mathrm{~min}$ temporal resolution of the COMEDIE model, we perform additional linear interpolation between the 5 min batches to provide the continuous data. The model applied in the GNSSWARP software estimates ZWD rather than ZTD directly. Thus, we calculate $\mathrm{ZWD}_{\mathrm{COMEDIE}}$ :

$\mathrm{ZWD}_{\text {COMEDIE }}=\mathrm{ZTD}_{\text {COMEDIE }}-\mathrm{ZHD}$

using ZTD value from COMEDIE and ZHD from the model corresponding to the selected MF. The ZWD estimates are then constrained by the additional equation in a functional model:

$\operatorname{dZWD}(t)=\operatorname{ZWD}_{\text {COMEDIE }}(t)-\mathrm{ZWD}^{\prime}(t)$

where $\mathrm{ZWD}^{\prime}(t)$ is the ZWD estimated at epoch $t-1$. Please note that in the first epoch of processing the $Z W D^{\prime}(t=0)$ is taken from the current tropospheric model, so the equation is:

$\mathrm{dZWD}(t)=0$ 
Fig. 5 Sample time series for static, continuous kinematic and reinitialized kinematic coordinates for station LODZ and $\mathrm{UNB} 3 \mathrm{~m}$ variant
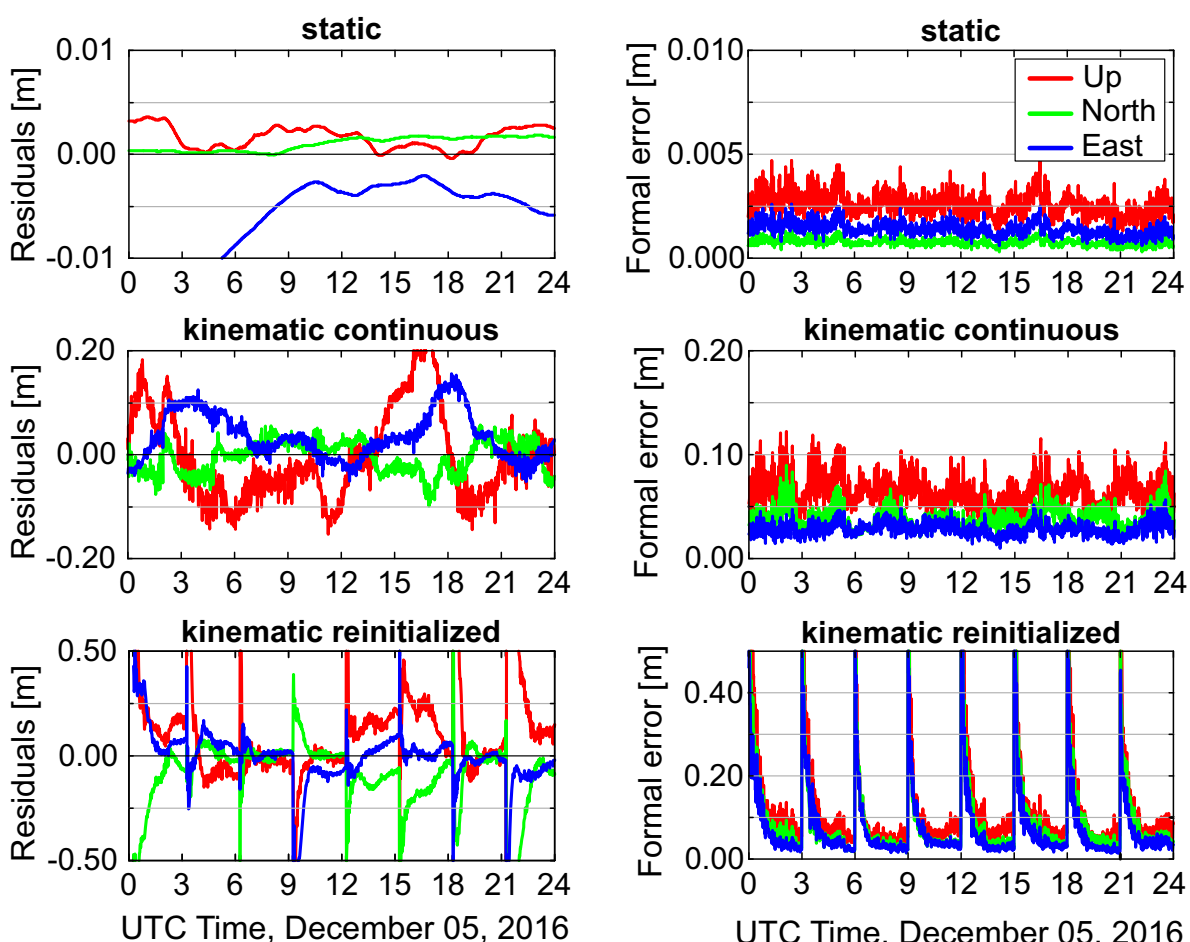

Table 3 Processing variants used in the framework of this study

\begin{tabular}{lllll}
\hline & Name & A priori ZTD & Constraining & MF \\
\hline 1. & UNB3m & UNB3m & None & UNB3m \\
2. & VMF1-FC & VMF1-FC & None & VMF1-FC \\
3. & WRFMF & WRF & None & WRFMF \\
4. & COMEDIE-UNB3m & COMEDIE & $10 \mathrm{~mm}$ & UNB3m \\
5. & COMEDIE-VMF1-FC & COMEDIE & $10 \mathrm{~mm}$ & VMF1-FC \\
6. & COMEDIE-WRFMF & COMEDIE & $10 \mathrm{~mm}$ & WRFMF \\
\hline
\end{tabular}

but in subsequent epochs, the $Z W D^{\prime}$ is:

$\mathrm{ZWD}^{\prime}(t)=\mathrm{ZWD}^{\prime}(t-1)+\mathrm{dZWD}(t-1)$

The ZWD constraining in variants $4-6$ is set to $10 \mathrm{~mm}$, which is the average SDs of residuals $\mathrm{ZTD}_{\mathrm{EPN}}-$ $\mathrm{ZTD}_{\text {COMEDIE }}$ as shown in Fig. 2. The first three variants are not constrained, because the spatiotemporal resolution and ZTD accuracy declared by the providers of UNB3m, VMF1-FC and WRF models are not sufficient for constraining, and those models should only be used as a priori ZTD models.

\section{Case study: application of the high-resolution models to PPP}

In the study, we use the simulated real-time mode of GNSS-WARP software to process $1 / 30 \mathrm{~Hz}$ GPS-only data from 14 Polish EPN stations, with elevation cutoff angle set to $5^{\circ}$. We applied the presented tropospheric models and MFs into PPP solutions. We processed three data periods, with calm, standard and severe tropospheric conditions, and obtain static, kinematic and reinitialized kinematic positions in six processing variants described in the previous section. The results of our processing are validated against the official EPN coordinates, which are obtained from the respective weekly combined EPN positions product (www.epncb.oma.be).

\section{Static positioning}

The results of the static positioning are presented to analyze the quality of solutions obtained for six variants at the most precise level. In our analysis, we remove the first $2 \mathrm{~h}$ of the results, assuming this period is the time required for the solution to converge.

We calculate the 3D mean value of residuals, for each station and each time period separately as a measure of systematic error (Fig. 6) and 3D SDs of residuals for each station and time period as a measure of coordinate 

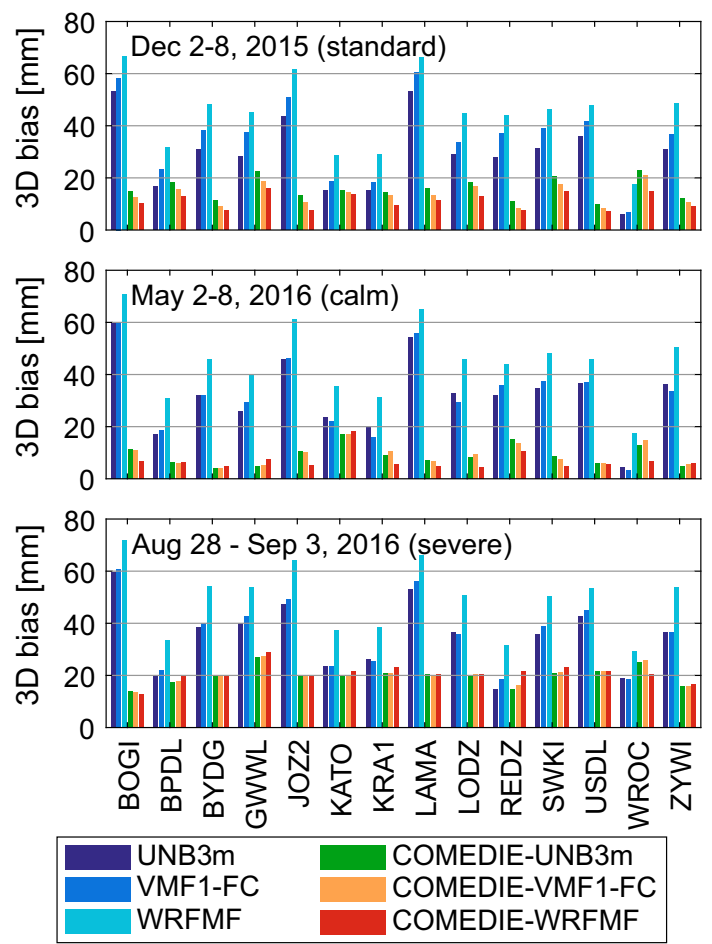

Fig. 6 Mean 3D biases of static coordinate residuals for 14 Polish EPN stations for three data periods

repeatability over time (Fig. 7). Table 4 presents the mean biases, SDs and root-mean-square errors (rms) averaged from all stations and periods for all variants, in order to assess the impact of using the particular models.

Table 4 shows that residuals statistics for North and East components are almost exactly the same for all variants. Thus, the Up component has the biggest influence on the 3D statistics. The Up biases for the COMEDIE-based variants are much smaller than for the standard variants, with the lowest average bias almost equal to 0 for COMEDIE-WRFMF. The Up biases are directly reflected in the 3D biases, where again the application of COMEDIE-based variants results in the smallest biases, with the best value of $12.9 \mathrm{~mm}$ for COMEDIE-WRFMF. Unfortunately, the Up SDs and consequently the 3D SDs for the COMEDIE-based variants are larger than for the standard variants by about $1.5 \mathrm{~mm}$. The reason for such behavior is that ZTD $_{\text {COMEDIE }}$ exhibits a small linear trend with respect to the reference $Z_{T D} D_{\text {EPN }}$. Thus, the initial values of the ZTD $_{\text {COMEDIE }}$ will always be slightly inaccurate, which is visible in the static mode, but negligible in the kinematic mode.

One can conclude that the accuracy, reflected in 3D biases, of the COMEDIE-based variants is much better, although the coordinate repeatability for those variants is slightly worse than for the standard variants. In our opinion, the gain of having much more accurate coordinates exceeds the loss of slightly worse coordinate repeatability.
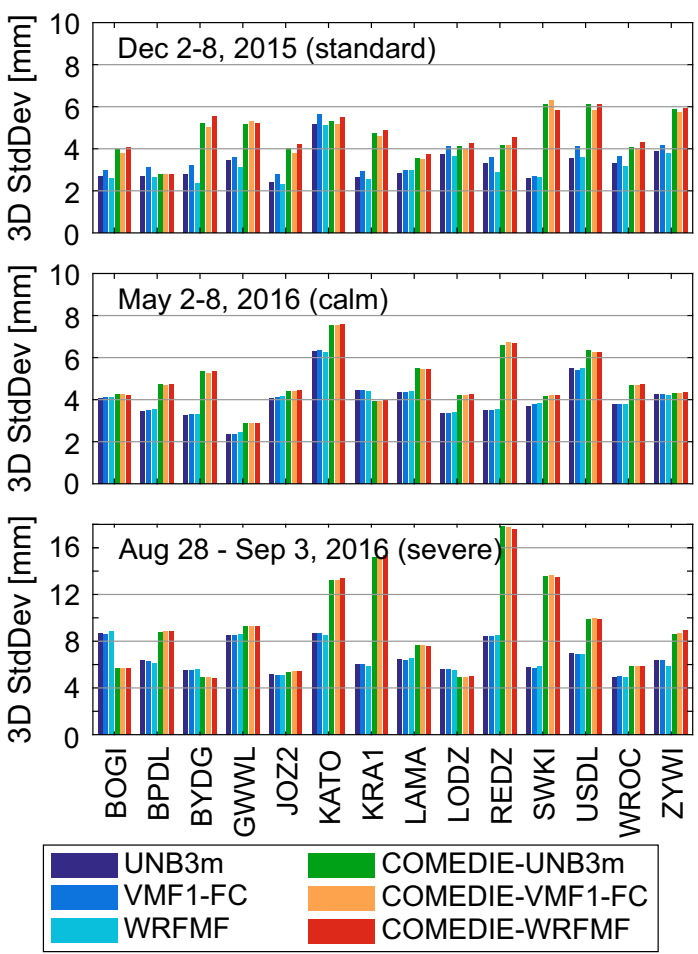

Fig. 7 Mean 3D SDs of static coordinate residuals for 14 Polish EPN stations for three data periods

Table 4 also presents the rms, which combines the information contained in bias and SD together. Once again, the COMEDIE-based variants exhibit the smallest 3D rms, affected mostly by the Up rms.

Figures 6 and 7 present the 3D biases and SDs, respectively, but with the division into the three considered periods. The 3D biases for the standard variants are less dependent on the chosen period than for the COMEDIEbased variants. For calm and standard tropospheric conditions, the COMEDIE-WRFMF exhibits the smallest biases for most of the stations, while for severe troposphere conditions, the COMEDIE-UNB3m and COMEDIEVMF1-FC variants are better. Moreover, for the severe period, the static 3D SDs for COMEDIE-based models are much larger than for the standard variants, although there are stations like LODZ, BOGI and BYDG where the 3D SDs for COMEDIE-based variants are smaller than for the remaining ones. We can attribute this feature to the fact that these stations are surrounded by many other GNSS stations. Thus, there is a larger input of GNSS data to the model, which results in having more accurate and precise ZTD model.

\section{Kinematic positioning}

Kinematic PPP is expected to benefit from ZTD constraining, because one of the highly correlated and originally unconstrained parameter, namely tropospheric delay, 
Table 4 Mean biases, SDs and rms for static coordinate residuals averaged from all 14 stations and three periods

\begin{tabular}{|c|c|c|c|c|c|c|c|c|c|c|c|c|}
\hline Name & $\begin{array}{l}N \text { bias } \\
(\mathrm{mm})\end{array}$ & $\begin{array}{l}E \text { bias } \\
(\mathrm{mm})\end{array}$ & $\begin{array}{l}\text { Up bias } \\
(\mathrm{mm})\end{array}$ & $\begin{array}{l}\text { 3D bias } \\
(\mathrm{mm})\end{array}$ & $\begin{array}{l}N \mathrm{SD} \\
(\mathrm{mm})\end{array}$ & $\begin{array}{l}E \mathrm{SD} \\
(\mathrm{mm})\end{array}$ & $\begin{array}{l}\text { Up SD } \\
(\mathrm{mm})\end{array}$ & $\begin{array}{l}\text { 3D SD } \\
(\mathrm{mm})\end{array}$ & $\begin{array}{l}N \mathrm{rms} \\
(\mathrm{mm})\end{array}$ & $\begin{array}{l}E \mathrm{rms} \\
(\mathrm{mm})\end{array}$ & $\begin{array}{l}\text { Up rms } \\
(\mathrm{mm})\end{array}$ & $\begin{array}{l}\text { 3D rms } \\
(\mathrm{mm})\end{array}$ \\
\hline $\mathrm{UNB} 3 \mathrm{~m}$ & -2.1 & 6.7 & -29.5 & 32.6 & 1.7 & 3.2 & 2.7 & 4.6 & 4.8 & 9.8 & 29.8 & 33.0 \\
\hline VMF1-FC & -2.1 & 6.7 & -32.1 & 35.0 & 1.7 & 3.2 & 2.8 & 4.7 & 4.8 & 9.8 & 32.4 & 35.5 \\
\hline WRFMF & -2.0 & 6.7 & -44.6 & 46.4 & 1.7 & 3.2 & 2.6 & 4.6 & 4.8 & 9.8 & 44.7 & 46.7 \\
\hline $\begin{array}{l}\text { COMEDIE- } \\
\text { UNB3m }\end{array}$ & -2.2 & 6.8 & -6.6 & 14.9 & 1.7 & 3.2 & 4.9 & 6.3 & 4.8 & 9.9 & 10.5 & 16.4 \\
\hline $\begin{array}{c}\text { COMEDIE- } \\
\text { VMF1-FC }\end{array}$ & -2.3 & 6.8 & -5.4 & 14.2 & 1.7 & 3.2 & 4.9 & 6.3 & 4.8 & 9.9 & 9.7 & 15.8 \\
\hline $\begin{array}{l}\text { COMEDIE- } \\
\text { WRFMF }\end{array}$ & -2.3 & 6.8 & -0.4 & 12.9 & 1.7 & 3.2 & 5.0 & 6.4 & 4.8 & 9.9 & 8.4 & 14.6 \\
\hline
\end{tabular}

can be estimated rapidly with high accuracy. Similarly to our analysis in static positioning, we investigated the systematic error of estimated kinematic coordinates (Fig. 8) and their repeatability over time (Fig. 9) using the continuous kinematic processing results. Table 5 shows the mean biases, SDs and rms of residuals from all stations and periods for all variants.

Similarly to the static positioning case, in the kinematic processing the COMEDIE-based variants have the smallest 3D biases, as shown in Table 5. The smallest 3D bias of $14.2 \mathrm{~mm}$ is observed for the COMEDIE-UNB3m. For the standard UNB3m solution, the 3D bias equals to $25.2 \mathrm{~mm}$.
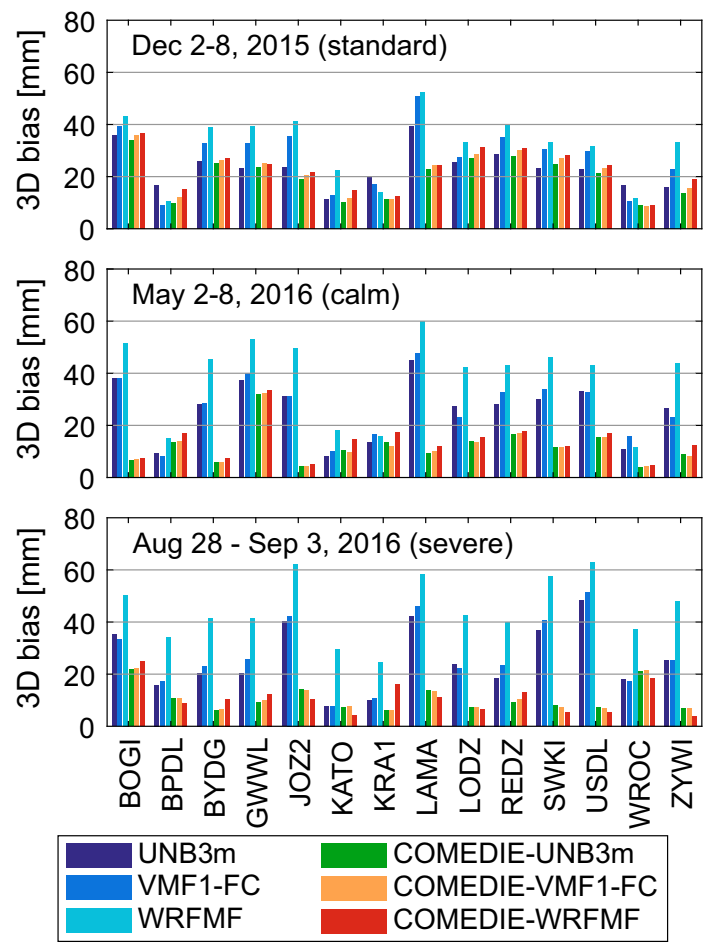

Fig. 8 Mean 3D biases of kinematic coordinate residuals for 14 Polish EPN stations for three data periods
Hence, we achieve more than $10 \mathrm{~mm}$ bias reduction. In the static positioning, the horizontal components statistics are almost identical, but in the kinematic case, the statistics for horizontal components vary with particular variants. The WRFMF variant exhibits the smallest SDs for North and East components. Also, the UNB3m and VMF1-FC variants have smaller North and East SDs than the COMEDIEbased variants by about $3 \mathrm{~mm}$. Even though COMEDIEUNB3m and COMEDIE-VMF1-FC have the smallest SDs of about $72 \mathrm{~mm}$ for the Up component, the variant with the smallest 3D SD is WRFMF. However, the differences in 3D SDs and rms between all variants vary within 4-5 mm
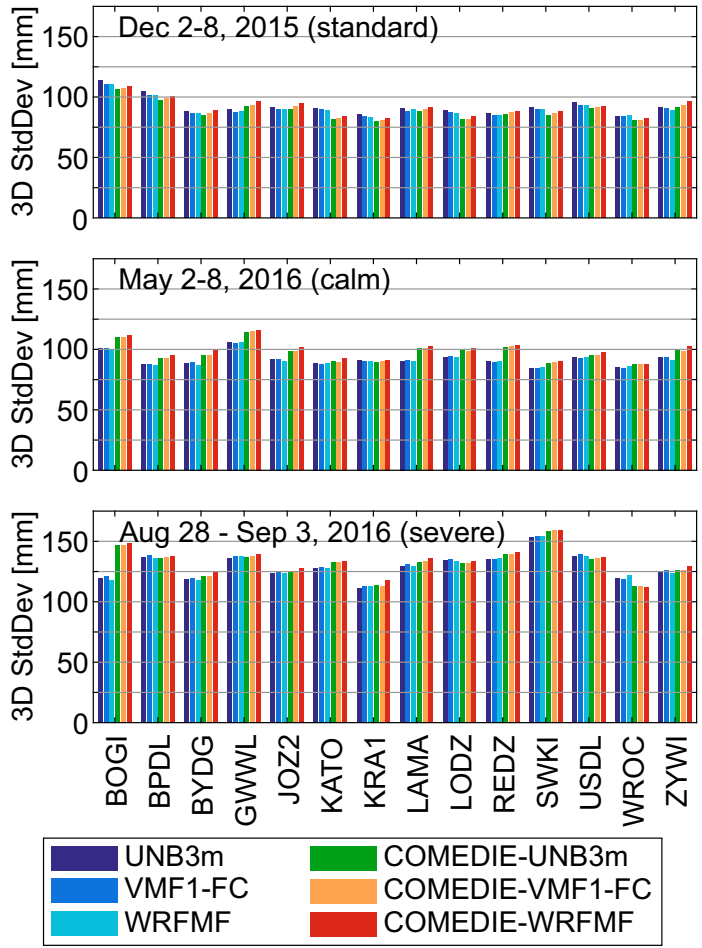

Fig. 9 Mean 3D SDs of kinematic coordinate residuals for 14 Polish EPN stations for three data periods 
Table 5 Mean biases, SDs and rms for kinematic coordinate residuals averaged from all 14 stations and three periods

\begin{tabular}{|c|c|c|c|c|c|c|c|c|c|c|c|c|}
\hline Name & $\begin{array}{l}N \text { bias } \\
(\mathrm{mm})\end{array}$ & $\begin{array}{l}E \text { bias } \\
(\mathrm{mm})\end{array}$ & $\begin{array}{l}\text { Up bias } \\
(\mathrm{mm})\end{array}$ & $\begin{array}{l}\text { 3D bias } \\
(\mathrm{mm})\end{array}$ & $\begin{array}{l}N \text { SD } \\
(\mathrm{mm})\end{array}$ & $\begin{array}{l}E \mathrm{SD} \\
(\mathrm{mm})\end{array}$ & $\begin{array}{l}\text { Up SD } \\
(\mathrm{mm})\end{array}$ & $\begin{array}{l}\text { 3D SD } \\
(\mathrm{mm})\end{array}$ & $\begin{array}{l}N \mathrm{rms} \\
(\mathrm{mm})\end{array}$ & $\begin{array}{l}E \mathrm{rms} \\
(\mathrm{mm})\end{array}$ & $\begin{array}{l}\text { Up rms } \\
(\mathrm{mm})\end{array}$ & $\begin{array}{l}\text { 3D rms } \\
(\mathrm{mm})\end{array}$ \\
\hline UNB3m & -0.8 & 5.1 & -17.3 & 25.2 & 38.3 & 62.7 & 73.3 & 104.4 & 38.7 & 64.1 & 77.0 & 107.9 \\
\hline VMF1-FC & -0.6 & 4.7 & -21.2 & 27.5 & 38.1 & 62.3 & 73.6 & 104.2 & 38.4 & 63.5 & 78.3 & 108.4 \\
\hline WRFMF & -0.2 & 4.1 & -35.8 & 38.5 & 37.5 & 62.0 & 73.3 & 103.8 & 37.9 & 63.3 & 82.8 & 111.4 \\
\hline $\begin{array}{l}\text { COMEDIE- } \\
\text { UNB3m }\end{array}$ & -1.9 & 7.5 & -1.6 & 14.2 & 41.8 & 65.0 & 71.7 & 105.9 & 42.0 & 66.6 & 72.1 & 107.2 \\
\hline $\begin{array}{l}\text { COMEDIE- } \\
\text { VMF1-FC }\end{array}$ & -2.1 & 8.1 & -1.1 & 14.7 & 41.9 & 65.4 & 72.0 & 106.4 & 42.2 & 67.2 & 72.4 & 107.9 \\
\hline $\begin{array}{l}\text { COMEDIE- } \\
\text { WRFMF }\end{array}$ & -2.5 & 9.9 & 2.1 & 15.9 & 42.7 & 66.6 & 73.3 & 108.3 & 42.9 & 68.6 & 73.7 & 109.9 \\
\hline
\end{tabular}

range. Thus, one may conclude that all those variants are very similar, taking into account the decimeter level of precision.

As shown in Figs. 8 and 9, considering the division into three periods, we conclude that the COMEDIE-based variants are the most suitable for kinematic positioning in the severe weather conditions, as the reductions of the $3 \mathrm{D}$ biases for the COMEDIE-based variants with respect to the standard variants are the largest for the severe period. Moreover, the 3D SDs are at a very similar level, except for the station BOGI, which can be attributed to the older equipment of Ashtech L1/L2 Choke Ring SNOW. For calm and standard atmosphere conditions, the gain of using the COMEDIE model as a priori ZTD is also visible, but the differences between COMEDIE-based and standard variants are on a smaller level.

\section{Convergence time}

Based on formal error, we analyze the time required for each solution to converge below the decimeter level, using the results of the reinitialized $3 \mathrm{~h}$ kinematic processing. We assume that the convergence is reached in a specific epoch if the formal error of the coordinate component remains below the specified level for at least $15 \mathrm{~min}$ afterward. Each $3 \mathrm{~h}$ batch is analyzed separately, and the results are averaged from all batches considering the division into three periods. Figure 10 shows the initialization time for $0.1 \mathrm{~m}$ level of convergence and 14 stations averaged from all three periods, while Fig. 11 shows the same information but for three periods separately and averaged from all 14 stations.

As shown in Figs. 10 and 11, the COMEDIE-based variants have shorter initialization times compared to the UNB3m, VMF1-FC or WRFMF variants regardless of the method of aggregation. All of the variants that use the a priori ZTD $_{\text {COMEDIE }}$ converge in a similar shortest time of about $58 \mathrm{~min}$ for horizontal components and $63 \mathrm{~min}$ for the vertical component, while the standard variants need about
$67 \mathrm{~min}$ for horizontal components and $79 \mathrm{~min}$ for the vertical component to converge below $0.1 \mathrm{~m}$. Thus, the convergence time for the variants that use $\mathrm{ZTD}_{\text {COMEDIE }}$ is $13 \%$ shorter for the horizontal components and $20 \%$ shorter for the vertical component than for the standard variants.

Finally, we investigated how long each solution and coordinate component take to converge below various levels within the range from $0.5 \mathrm{~m}$ to $0.1 \mathrm{~m}$. Figure 12 shows that on all levels, the COMEDIE-based variants have shorter convergence time than the standard variants. For the $0.1 \mathrm{~m}$ level of convergence and horizontal components, all COMEDIE-based solutions converged within the fixed $3 \mathrm{~h}$ periods. For the standard variants, it is $99 \%$ of the solutions. Thus, there is no significant difference between the number of converged solutions for a particular variant. For the vertical component and COMEDIE-based variants, $88 \%$ of the solutions converged within the $3 \mathrm{~h}$ period, while for the standard variants only $76 \%$ of solutions. Even for the largest level of $0.5 \mathrm{~m}$, where all solutions converged within the $3 \mathrm{~h}$ period, the convergence time for COMEDIE-based variants is shorter than for standard variants. Thus, the advantage of using the COMEDIE model is still evident. Consequently, we benefit of using the COMEDIE model in two ways-shortening the convergence time and having more converged solutions.

Using the COMEDIE model to constrain the solution is sufficient for shortening the convergence time. The choice of the MF does not influence the time required for the solution to converge in a significant matter. Thus, only constraining the PPP with high-resolution ZTD model is essential for shortening the convergence time.

\section{Summary}

We analyzed the impact of different a priori models and mapping functions on the determination of positioning components and convergence time in real-time PPP. Our 

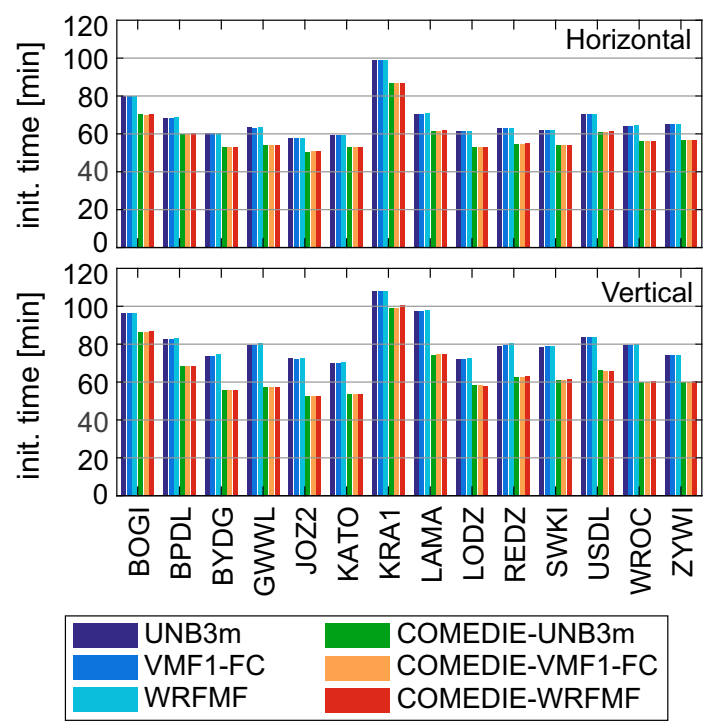

Fig. 10 Initialization time based on formal error for $0.1 \mathrm{~m}$ level of convergence for 14 Polish EPN stations averaged from three periods

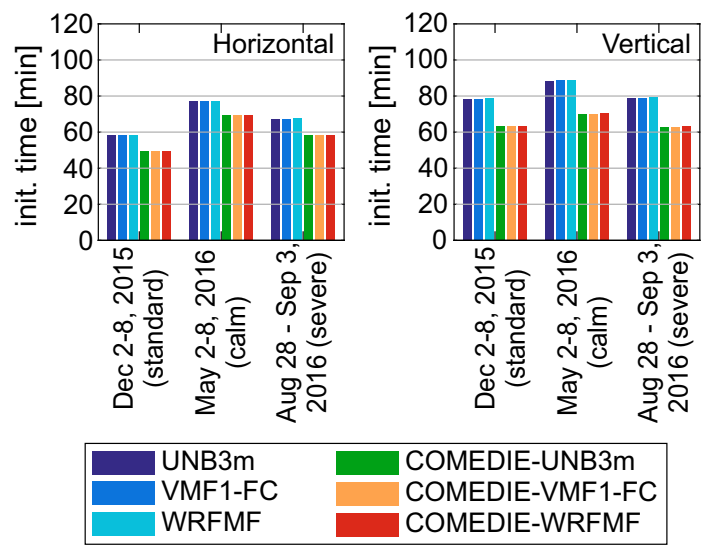

Fig. 11 Initialization time based on formal error for $0.1 \mathrm{~m}$ level of convergence for three periods averaged from 14 Polish EPN stations

study was conducted for 14 Polish EPN stations during three periods. We calculated the North, East and Up coordinates of the stations using the tropospheric models in six processing variants: two commonly used variants using UNB3m and VMF1-FC models, WRFMF variant with a priori model and MF calculated from WRF data and three variants where COMEDIE-derived ZTDs were used as a priori troposphere and to constrain tropospheric estimates. In the latter variants, also three different MFs were used, UNB3m, VMF1-FC and WRFMF.

We estimated three types of coordinates, namely static, continuous kinematic and reinitialized kinematic. For the static processing, the 3D biases for the COMEDIE-based variants were about $20 \mathrm{~mm}$ smaller than those for the standard variants, but the COMEDIE-based 3D SDs were about $1.5 \mathrm{~mm}$ larger than the standard variants. For North and East components, the statistics were very similar for all
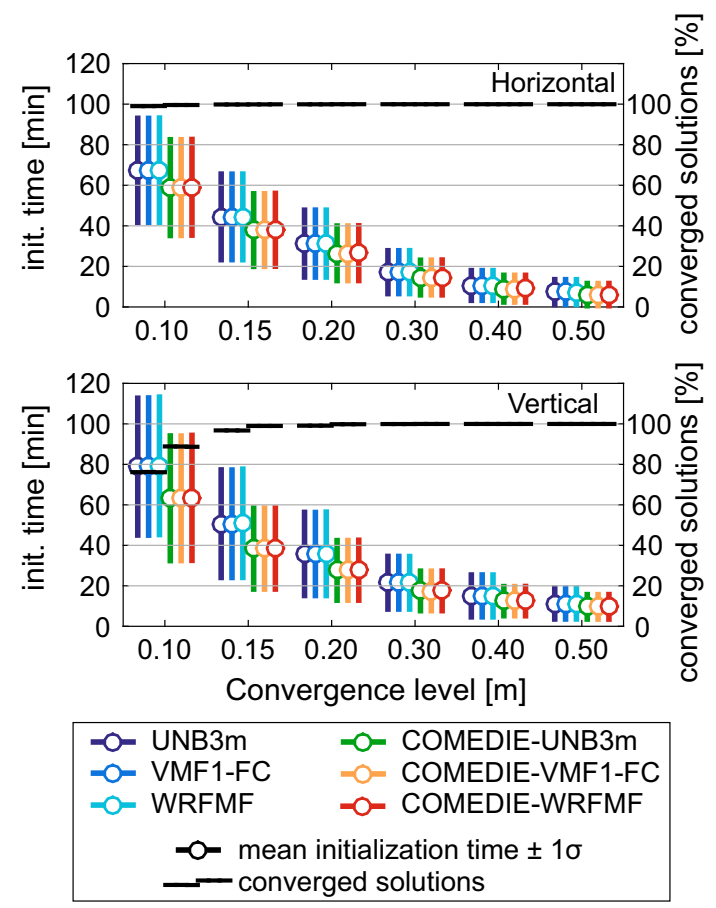

Fig. 12 Mean biases and SDs of initialization times for various levels of convergence averaged from 14 Polish EPN stations and three data periods

variants. Thus, the 3D statistics for the static processing are a direct reflection of vertical component behavior.

In the kinematic processing, the UNB3m, VMF1-FC and WRFMF variants exhibited the best statistics for the horizontal components, while the COMEDIE-based variants were better in terms of vertical component. The 3D biases for the COMEDIE-based variants were about $10 \mathrm{~mm}$ smaller than for the standard variants, while the 3D SDs for all variants differ within the $4 \mathrm{~mm}$ range. The COMEDIEbased variants are also the most suitable for positioning in the severe weather conditions, as the differences in $3 \mathrm{D}$ biases were the most visible in this period.

Moreover, we investigated the convergence time for all variants and various convergence levels from 0.5 to $0.1 \mathrm{~m}$. For $0.1 \mathrm{~m}$ level of convergence, the application of COMEDIE-based variants resulted in shortening the convergence time by $13 \%$ for horizontal components and $20 \%$ for the vertical component than for the standard variants. Additionally, the percentage of converged solutions increased from $76 \%$ for standard variants to $88 \%$ for COMEDIE-based variants for vertical component.

Our conclusion is that the best option for real-time PPP is to constrain tropospheric estimates with high-resolution ZTD model as it leads to the best accuracy and the shortest convergence time at the expense of slightly worse precision. The choice of mapping function has a small impact on positioning results. The proposed ZTD and MF models based on WRF analysis can be established as a service 
supporting real-time PPP users with VMF-like product, but with better accuracy as well as higher spatial and temporal resolution, sufficient for troposphere constraining.

Acknowledgements This work has been supported by COST Action ES1206 GNSS4SWEC (gnss4swec.knmi.nl), the Polish National Science Centre (2014/15/N/ST10/00824, 2014/15/B/ST10/00084) and the Wroclaw Center for Networking and Supercomputing (www. wcss.wroc.pl, computational grant for MATLAB Software License No: 101979). The COMEDIE software was originally developed at ETH Zürich. We acknowledge EPN (http://www.epncb.oma.be) for providing station coordinates and tropospheric products, Jan Kaplon for providing near real-time ZTD, Maciej Kryza for providing WRF, Leica Poland and the Head Office of Geodesy and Cartography for providing GNSS data.

Open Access This article is distributed under the terms of the Creative Commons Attribution 4.0 International License (http://creative commons.org/licenses/by/4.0/), which permits unrestricted use, distribution, and reproduction in any medium, provided you give appropriate credit to the original author(s) and the source, provide a link to the Creative Commons license, and indicate if changes were made.

\section{References}

Boehm J, Schuh H (2004) Vienna mapping functions in VLBI analyses. Geophys Res Lett 31(1):L01603

Boehm J, Kouba J, Schuh H (2009) Forecast Vienna Mapping Functions 1 for real-time analysis of space geodetic observations. J Geod 83(5):397-401

Bosy J, Kapłon J, Rohm W, Sierny J, Hadas T (2012) Near real-time estimation of water vapour in the troposphere using ground GNSS and the meteorological data. Ann Geophys 30(9):1379-1391

Dach R, Lutz S, Walser P, Fridez P (2015) Bernese GNSS software version 5.2. Astronomical Institute, University of Bern

de Oliveira PS, Morel L, Fund F, Legros R, Monico JFG, Durand S, Durand F (2017) Modeling tropospheric wet delays with dense and sparse network configurations for PPP-RTK. GPS Sol 21(1):237-250

Douša J, Dick G, Kačmařík M, Brožková R, Zus F, Brenot H, Stoycheva A, Möller G, Kaplon J (2016) Benchmark campaign and case study episode in central Europe for development and assessment of advanced GNSS tropospheric models and products. Atmos Meas Tech 9(2989-3008):2016. doi:10.5194/amt-92989-2016

Eckert V, Cocard M, Geiger A (1992a) COMEDIE: (Collocation of meteorological data for interpretation and estimation of tropospheric pathdelays) Teil I: Konzepte, Teil II: Resultate. Technical report 194, ETH Zürich. Grauer Bericht

Eckert V, Cocard M, Geiger A (1992b) COMEDIE: (Collocation of meteorological data for interpretation and estimation of tropospheric pathdelays) Teil III: Software. Technical report 195, ETH Zürich. Grauer Bericht

Essen L, Froome K (1951) The refractive indices and dielectric constants of air and its principal constituents at $24,000 \mathrm{mc} / \mathrm{s}$. Proc Phys Soc Sect B 64(10):862

Ge M, Gendt G, Rothacher M, Shi C, Liu J (2008) Resolution of GPS carrier-phase ambiguities in precise point positioning (PPP) with daily observations. J Geod 82(7):389-399

Guerova G, Jones J, Douša J et al (2016) Review of the state of the art and future prospects of the ground-based GNSS meteorology in Europe. Atmos Meas Tech 9:5385-5406
Hadas T (2015) GNSS-Warp software for real-time precise point positioning. Artif Satell 50(2):59-76

Hadas T, Kaplon J, Bosy J, Sierny J, Wilgan K (2013) Near real-time regional troposphere models for the GNSS precise point positioning technique. Meas Sci Technol 24(5):055003

Herring TA (1992) Modeling atmospheric delays in the analysis of space geodetic data. In: De Munck JC, Spoelstra TA (eds) Proceedirws of refraction of transatmospheric simals in Geodesy, vol 36. Netherlands Geodetic Commission Publications on Geodesy

Hobiger T, Ichikawa R, Koyama Y, Kondo T (2008) Fast and accurate ray-tracing algorithms for real-time space geodetic applications using numerical weather models. J Geophys Res Atmos 113:D20302

Hurter F, Maier O (2013) Tropospheric profiles of wet refractivity and humidity from the combination of remote sensing data sets and measurements on the ground. Atmos Meas Tech 6(11):3083-3098

IERS Conventions (2010) Petit G, Luzum B (eds) (IERS technical note; 36) Frankfurt am Main: Verlag des Bundesamts für Kartographie und Geodäsie. ISBN 3-89888-989-6

Ibrahim H, El-Rabbany A (2011) Performance analysis of NOAA tropospheric signal delay model. Meas Sci Technol 22:115107

Kouba J (2008) Implementation and testing of the gridded Vienna Mapping Function 1 (VMF1). J Geod 82(4-5):193-205

Kouba J (2015) A guide to using International GNSS Service (IGS) products. http://kb.igs.org/hc/en-us/article_attachments/ 203088448/UsingIGSProductsVer21_cor.pdf

Kryza M, Werner M, Wałaszek K, Dore AJ (2013) Application and evaluation of the WRF model for high-resolution forecasting of rainfall — a case study of SW Poland. Meteorol Z 22(5):595-601

Leandro RF, Santos MC, Langley RB (2006) UNB neutral atmosphere models: development and performance. In: Proceedings of ION NTM 2006. Institute of Navigation, Monterey, pp 564-573

Li X, Zhang X, Ge M (2011) Regional reference network augmented precise point positioning for instantaneous ambiguity resolution. J Geophys Res 85:151-158

Li X, Ge M, Douša J, Wickert J (2014) Real-time precise point positioning regional augmentation for large GPS reference networks. GPS Solut 18(1):61-71

Mervart L, Lukes Z, Rocken C, Iwabuchi T (2008) Precise point positioning with ambiguity resolution in real-time. In: Proceedings of ION GNSS 2008. Institute of Navigation. Savannah, Sept 16-19, pp 397-405

Niell AE (1996) Global mapping functions for the atmosphere delay at radio wavelengths. J Geophys Res 101(B2):3227-3246

Rocken C, Sokolovskiy S, Johnson JM, Hunt D (2001) Improved mapping of tropospheric delays. J Atmos Ocean Technol 18(7):1205-1213

Rüeger JM (2002) Refractive index formulae for radio waves. In: Proceedings, FIG technical program, XXII FIG international congress. Washington, pp 19-26

Saastamoinen J (1973) Contributions to the theory of atmospheric refraction, part II. Bull Geod 107(1):13-34

Shepard D (1968) A two-dimensional interpolation function for irregularly-spaced data. In: Proceedings of 23rd ACM national conference, pp 517-524

Shi J, Xu C, Guo J, Gao Y (2014) Local troposphere augmented for real-time precise point positioning. Earth Planets Space 66(1):1-13

Skamarock WC, Klemp JB, Dudhia J, Gill DO, Barker DM, Duda MG, Huang XY, Wang W, Powers JG (2008) A description of the advanced research WRF version 3. NCAR tech. note NCAR/ TN-475+STR. doi:10.5065/D68S4MVH 
Snajdrova K, Boehm J, Willis P, Haas R, Schuh H (2006) Multitechnique comparison of tropospheric zenith delays derived during the CONT02 campaign. J Geod 79:613-623

Troller M, Geiger A, Bürki B, Kahle HG (2003) 4 Dimensional meteorological modelling of pathdelays (COMEDIE). In: Swiss national report on the geodetic activities in the years 1999-2003, presented to the IUGG General Assembly XXIII in Sapporo, Japan. ISSN 3-908440-06-8, Swiss Geodetic Commission, pp 23-24

U.S. Atmosphere (1976) NASA TM-X 74335. National Oceanic and Atmospheric Administration, National Aeronautics and Space Administration and United States Air Force

Urquhart L, Nievinski FG, Santos MC (2014) Assessment of tropospheric mapping functions using three-dimensional raytracing. GPS Solut 18(3):345-354. doi:10.1007/s10291-0130334-8

Wilgan K, Hurter F, Geiger A, Rohm W, Bosy J (2017) Tropospheric refractivity and zenith path delays from least-squares collocation of meteorological and GNSS data. J Geod 91(2):117-134. doi:10.1007/s00190-016-0942-5

Yao Y, Yu C, Hu Y (2014) A new method to accelerate PPP convergence time by using a global zenith troposphere delay estimate model. J Navig 67(5):899-910

Zus F, Dick G, Dousa J, Heise S, Wickert J (2014) The rapid and precise computation of GPS slant total delays and mapping factors utilizing a numerical weather model. Radio Sci 49(3):207-216

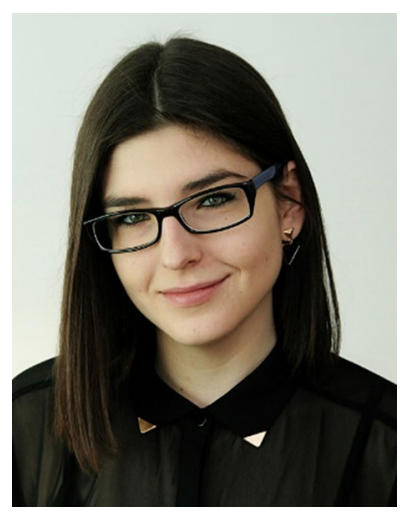

Karina Wilgan graduated in Mathematics in 2011. Since 2012, she is a Ph.D. student in the field of geodesy and cartography. Her scientific interests are focused on GNSS meteorology, with particular emphasis on troposphere and numerical weather prediction.

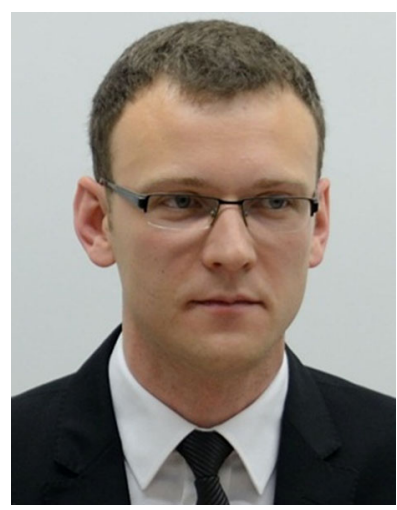

Tomasz Hadas received his Ph.D. in satellite geodesy in 2015. He is working on the development of GNSS real-time precise positioning algorithms, troposphere modeling in real time and application of atmosphere models into GNSS positioning.

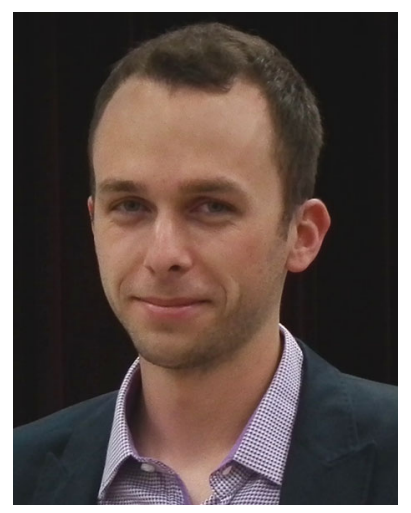

Pawel Hordyniec is a Ph.D. student in the field of geodesy and cartography since 2013 . His area of research is GPS radio occultation technique and signal ray-tracing for ground- and space-based GNSS applications.

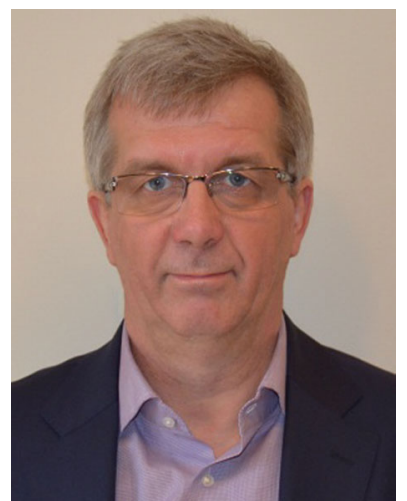

Jaroslaw Bosy is a Full Professor of Technical Sciences since 2014. His research is concentrated on using GNSS techniques to derive information about the state of the atmosphere and the applications of GNSS technique in geodesy and geodynamics. 